\title{
Understanding Pressure Shielding by Canopies
}

\author{
Nandita Nurani Hari ${ }^{1}$, Máté Szőke ${ }^{2}$ and William J. Devenport, ${ }^{3}$ \\ Center of Research in Experimental Aero/hydrodynamic Technology (CREATe), \\ Department of Aerospace and Ocean Engineering, Virginia Tech, Blacksburg, VA 2406, USA
}

\author{
Stewart Glegg ${ }^{4}$ \\ Department of Ocean and Mechanical Engineering, \\ Florida Atlantic University, Boca Raton, FL 33431, USA
}

\begin{abstract}
Previous studies have demonstrated that structures such as a canopy or finlets placed within a boundary layer over an aerodynamic surface can attenuate pressure fluctuations on the surface without compromising aerodynamic performance. This paper describes research into the fundamental mechanisms of this pressure shielding. Experiments and analysis are performed on elemental canopy configurations which are arrays of streamwise rods placed parallel to the wall in order to eliminate the confounding effects of a leading edge support structure. Experiments show that such a canopy produces attenuation in three distinct frequency ranges. At low frequencies, where convective scales are much greater than the canopy height, attenuation spectra scale on the canopy height Strouhal number, but at high frequencies, a dissipation type frequency scaling appears more appropriate. There is midfreqeuncy region which shows reduction in attenuation and is observed for all canopy structures tested. Attenuation in this region appears to scale with Strouhal number based on canopy spacing.
\end{abstract}

\section{Introduction}

Surface pressure fluctuations originating from turbulence manifest as trailing edge noise on wind turbines, leading edge noise on helicopter blades or cabin noise in passenger aircraft, among many other consequences. Passive surface treatments that shield aerodynamic surfaces from turbulent fluctuations while maintaining the wall normal transport and low drag, would be of great benefit to these applications. Prior studies have designed surface treatments by a combination of biological inspiration and heuristic methods. However, the fundamental physical and mathematical outlining this mechanism, termed as pressure shielding is not yet entirely understood.

Recent work by Clark et al (2016) showed the effectiveness of canopies made using a parallel array of streamwise oriented fibers as shown in Figure 1. These were inspired by the downy feathers on owl wings and characterized by an open-area ratio of $70 \%$. When placed in a wall jet at about $40 \%$ of the boundary layer thickness, the fibers shielded surface roughness from the turbulent flow by reducing the surface pressure fluctuations over $20 \mathrm{~dB}$ at higher frequencies, and hence the surface noise. This new method was adapted to so-called finlet and rail configurations compatible with airfoil trailing edges. These were then tested by installing them on the trailing edge of DU96-W180 airfoil in a study by Clark et al (2017). This study showed reduction of trailing edge noise by suppressing wall pressure fluctuations without altering the boundary layer or substantially increasing aerodynamic drag. Experiments by Millican et al (2017) and Afshari et al $(2016,2017)$ on different finlets and rail configurations showed formation of shear layer along with increased turbulence levels at the height of finlet/rail. These were further investigated by

\footnotetext{
${ }^{1}$ Graduate Research Assistant.

${ }^{2}$ Senior Research Associate

${ }^{3}$ Professor, Associate Fellow AIAA.

${ }^{4}$ Professor, Associate Fellow AIAA.
} 


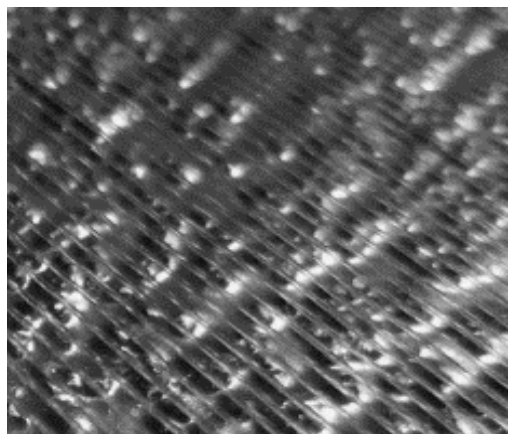

Figure 1. Streamwise oriented fibers used to provide pressure shielding of a rough surface immersed in a turbulent boundary layer. Clark et al. (2016)
Bolding et al (2017), who performed large eddy simulation to confirm reduction in surface fluctuations without significant impact on the aerodynamics.

The work described in this paper follows from the study of Gonzalez et al. (2019) to understand the mechanisms of pressure shielding through experimental and theoretical work. They performed experimental and computational analysis on elemental canopy configurations which are parallel arrays of streamwise rods that eliminate effects of leading edge support structure or an entrance condition. Gonzalez et al (2019) use dimensional analysis to reduce large number of parameters affecting the flow to certain meaningful non-dimensional quantities that could explain the presence of different pressure shielding mechanisms. Few significant non-dimensional parameters that have been investigated are streamwise distance from the leading edge normalized over canopy height, $\Delta x / h$, frequency scaling based on canopy height that is shown to be effective at lower frequency range given by $f h / U$ and dissipative scaling of

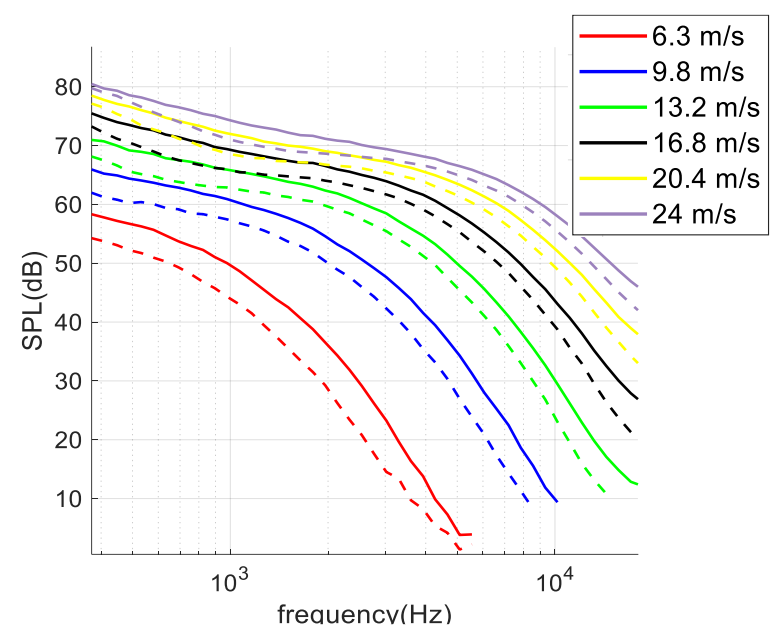

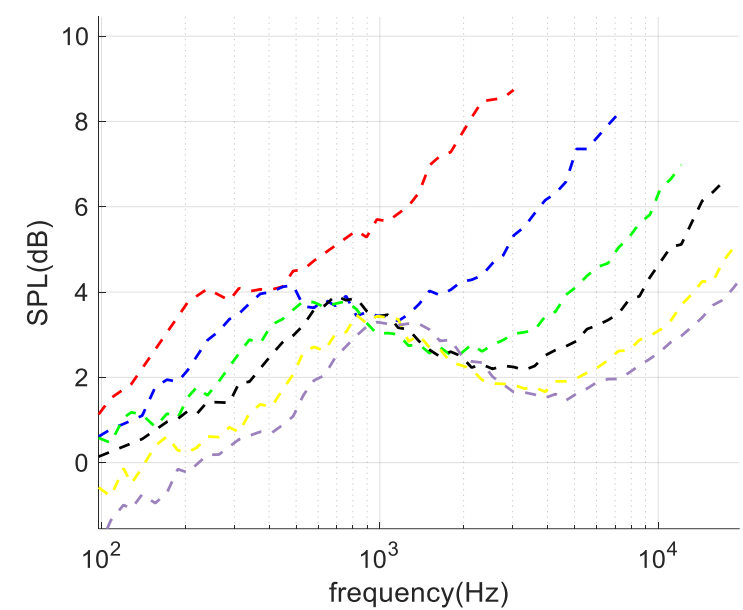

Figure 2: a) SPL and b) attenuation ( $\triangle S P L)$ vs frequency $(\mathrm{Hz})$ showing comparison of surface spectra for clean wall (solid-lines) and canopy configuration 1 (dashed lines) at $h=4 \mathrm{~mm}$ measured at $\Delta x=95.3 \mathrm{~mm}(\Delta x / \mathrm{h}=$ 21.9) for six different flow velocities [Gonzalez et al (2019)]

frequency given by $f v / U_{h}^{2}$. Analysis showed canopy produced attenuation in two distinct frequency regions. At low frequencies below about $1 \mathrm{kHz}$, attenuation scaled on Strouhal number based on canopy height, and higher frequency attenuation beyond 3-6 kHz appears to follow dissipation type of scaling. This was supported by RANS calculations which simulated the canopy geometry as is and also as a porous layer. Figure 2 shows the surface pressure spectra for a smooth wall (solid line) and spectra when canopy is placed parallel to the wall (dashed line) for different boundary layer edge velocities at leading edge. Figure $2 b$ shows the corresponding attenuation. This is a representative case from the results presented by Gonzalez et al (2019). At lower frequencies, the attenuation varies uniquely with streamwise distance normalized over the canopy height, $\Delta x / h$ and saturates to become invariant beyond a certain downstream distance. 


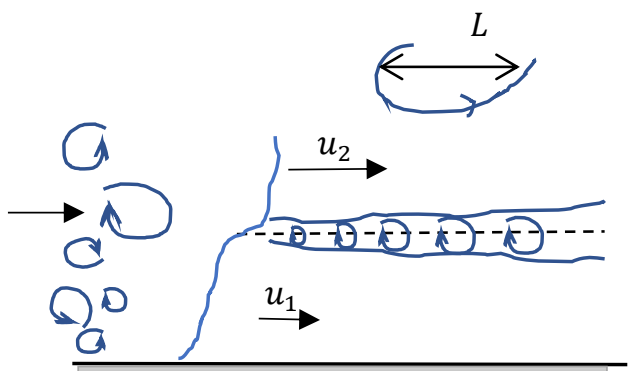

a)

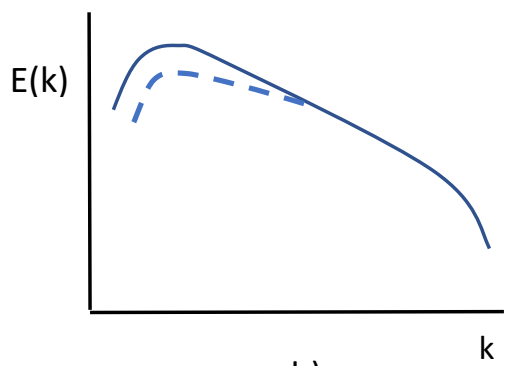

b)

Figure 3a) Schematic showing shear-sheltering hypothesis due to the presence of canopy in a turbulent shear flow Figure $3 b$ ) possible variation in surface pressure spectra

At low frequencies, they hypothesized that the canopy-generated shear layer blocks pressure-producing disturbances from entering further towards the wall than the canopy. This range implies convective scales that are large compared to the canopy height. This aligns with the shear-sheltering mechanism, first proposed by Jacobs and Durbin (1998) who found that boundary layer shear prevented free-stream instabilities and therefore associated pressure perturbations from penetrating into the shear layer. (Rapauch et al 1996, Hunt et al 1999). Figure 3a shows a schematic of shear generation by the canopy in a turbulent flow which is hypothesized to prevent large scale perturbations present in the outer layer from propagating through the shear layer. Figure $3 \mathrm{~b}$ shows the possible effect of this shear layer associated with the canopy on the surface pressure spectrum due to reduction in the energy containing large-scale structures. The canopy perhaps dampens the wall-normal fluctuations (Lumley, 1969) and also reduces the integral length scales associated with the flow (Ptasinki (2003)), therefore reducing interaction between turbulence above and below the canopy, which leads to blocking of some of the fluctuations from propagating below canopy (Finnigan 2000, Belcher et al 2003,2012). The presence of mean shear could further strengthen this process (Ptasinki (2003)). At high frequencies, Gonzalez et al (2019) hypothesized that the spectral shortcut mechanism proposed by Lilley (1998) was responsible for the attenuation of pressure fluctuations. The spectral shortcut which is due to enhanced dissipation i.e. transfer of energy from large to small scales due to the presence of canopy microstructure that generates intense turbulence at smaller scales. (Lilley, 1998) Figure 4 shows turbulent kinetic energy spectrum due to a forest canopy (Kaiman and Finnigan, 1994) which shows increased turbulence production at lower scales due to canopy wake and increased dissipation due to spectral-shortcut.

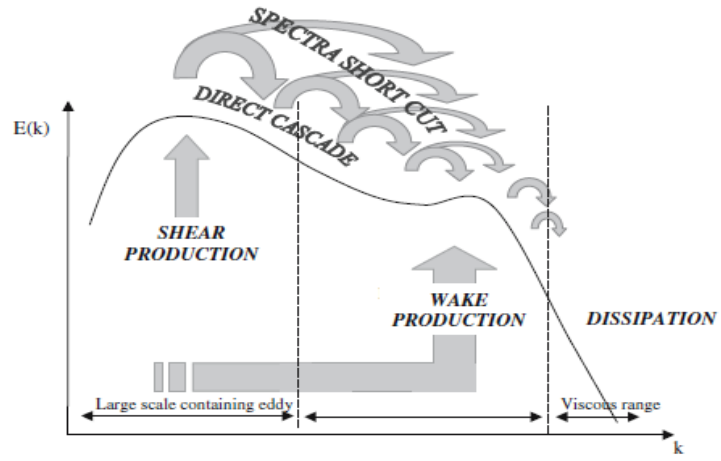

Figure 4 Schematic showing the variation in the TKE spectrum due to forest canopies (Poggi 2006, Kaiman and Finnigan, 1994)

The objective of this paper is to establish a deeper understanding of the pressure shielding mechanisms. We present experimental results and analysis that support fundamental new findings concerning hypotheses governing both lower and higher frequency ranges. The study extends the work of Gonzalez et al, 2019. Section II describes the series of experiments that focuses on unsteady surface pressure measurements and flow measurements for different canopy configurations. Different test cases were experimented by varying both flow and geometric parameters. Section III describes the experimental results and analysis followed up by discussion on establishing the above-mentioned hypotheses for different frequency regions of attenuation. 


\section{Experimental Setup}

The low-speed Anechoic Wall Jet facility at Virginia Tech (Kleinfelter et al. 2019) has been used for all experimentation. The facility provides a quiet environment two-dimensional turbulent flow over a wall, where various flow measurement techniques and devices can be used. Flow exhausts from a $1219 \mathrm{~mm}$ wide and $12.7 \mathrm{~mm}$ high rectangular nozzle at jet velocities ranging $20 \mathrm{~m} / \mathrm{s}$ through $70 \mathrm{~m} / \mathrm{s}$, within $\pm 0.1 \mathrm{~m} / \mathrm{s}$. The fully developed wall jet mean-velocity profile has been scaled using power-law relations proposed by Wygnanski et al (1992) given as:

$$
\begin{gathered}
\frac{U_{m}}{U_{j}}=A_{U} R e_{j}^{n+1} R e_{x}^{n} \\
\frac{\delta^{*}}{h_{j}}=A_{D} R e_{j}^{p-2} R e_{x}^{p} \\
\theta=B \delta^{*} \\
\delta=A \delta^{*}
\end{gathered}
$$

Where, $U_{j}$ is the jet velocity, $\delta^{*}$ represents displacement thickness, $\theta$, momentum thickness, $\delta$, boundary layer thickness and $U_{m}$ is the maximum velocity at boundary layer edge. $R e_{j}$ and $R e_{x}$ are Reynolds numbers based on nozzle height and streamwise distance, $x$ respectively. The origin of the coordinate system is the nozzle exit plane, with the positive $x$-axis facing downstream, positive y-axis as wall upward normal and the $z$-axis centered spanwise, following the right-hand coordinate system. The boundary layer parameters at the canopy leading edge are given in Table 1

Table 1: Boundary layer parameters measured at canopy leading location, $x=1.28 \mathrm{~m}$

$\begin{array}{cccc}\boldsymbol{U}_{\boldsymbol{j}}(\boldsymbol{m} / \boldsymbol{s}) & \boldsymbol{U}_{\boldsymbol{m}}(\boldsymbol{m} / \boldsymbol{s}) & \boldsymbol{\delta}(\boldsymbol{m} \boldsymbol{m}) & \boldsymbol{\delta}^{*}(\boldsymbol{m} \boldsymbol{m}) \\ \mathbf{2 0} & 6.34 & 16.0 & 1.00 \\ \mathbf{3 0} & 9.75 & 15.1 & 0.94 \\ \mathbf{4 0} & 13.24 & 14.4 & 0.90 \\ \mathbf{5 0} & 16.8 & 13.9 & 0.87\end{array}$

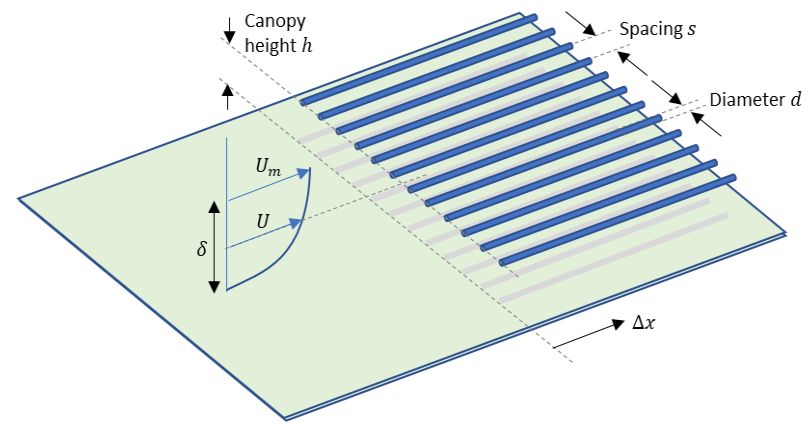

Figure 5 Schematic of a rod-canopy placed parallel to the wall in a boundary layer

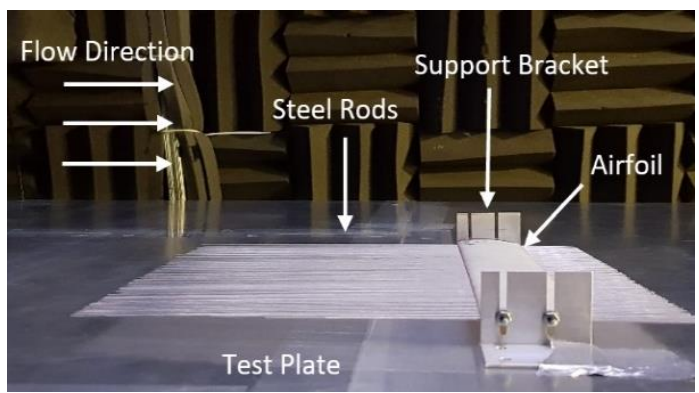

Figure 6: Image of canopy placed at parallel to the wall in the wall jet (Gonzalez et al (2019)) 
A canopy formed from a streamwise array of evenly spaced rods was used by Gonzalez et al (2019) which are cantilevered by an airfoil support designed for minimized shedding. Such a canopy design allowed the effectiveness of the canopy in reducing surface pressures to be isolated from the effects of leading-edge support structures, also called as entrance condition. Figure 5 shows the schematic of the canopies tested in this study. The rods are cantilevered to an airfoil support which is designed to produce minimum shedding and held by L-brackets on either sides as shown in Figure 6. Experiments were performed for six canopy configurations as listed in the Table 2. All canopies have been characterized based on rod diameter $(d)$, spacing $(s)$, defined as the distance between mid-points of two consecutive rods, open-area ratio $(s-d) / s$, which refers to the canopy density. Configurations A, B, D and E have the same open-area ratio however with varying diameter and spacing, while configurations $\mathrm{C}$ and $\mathrm{F}$ have relatively higher open-area ratio. The schematic of the wall plate in the facility and the coordinate system is as used by Gonzalez et al(2019). The canopy leading edge was placed at $x=1.28 \mathrm{~m}$ and is placed centered along the midspan of the wall-jet plate such that it fits well inside region of spanwise uniformity of flow.

Table 2: Canopy configurations tested

\begin{tabular}{|l|l|l|l|l|}
\hline $\begin{array}{l}\text { Canopy } \\
\text { Configuration }\end{array}$ & $\begin{array}{l}\text { Rod length } \\
(\mathbf{m m})\end{array}$ & $\begin{array}{l}\text { Rod } \\
\text { diameter } \\
\boldsymbol{d}(\boldsymbol{m m})\end{array}$ & $\begin{array}{l}\text { Rod } \\
\text { spacing } \\
\boldsymbol{s}(\boldsymbol{m m})\end{array}$ & $\begin{array}{l}\text { Open-area } \\
\text { ratio, } \\
(\boldsymbol{s}-\boldsymbol{d}) / \boldsymbol{s}\end{array}$ \\
\hline A & 1 & 3 & 0.66 \\
B & 152.4 & 1.56 & 3.64 & 0.66 \\
C & 152.4 & 1 & 4 & 0.75 \\
D & 152.4 & 2 & 6 & 0.66 \\
E & 254.0 & 3 & 9 & 0.66 \\
F & 254.0 & 1 & 8 & 0.88 \\
\hline
\end{tabular}

Surface pressure measurements were made for different test cases using a series of seventeen Knowles (FG-23329P07) microphones mounted flush to the wall. The microphones have a flat response between 100-20 kHz. Data from the microphones was acquired using six-channel Bruel and Kjaer Type 3050 24-bit LAN-XI modules. Post-processing was done using Fast Fourier Transform of the data sampled at $65,536 \mathrm{~Hz}$ of record length of 8192 multiplied by a $50 \%$ overlap Hanning window. Attenuation in surface pressure due to canopy is represented as $\triangle S P L$ computed as the difference between spectral levels measured under a smooth wall configuration and those measured with canopy placed over the wall, given by $10 \log _{10}\left(G_{p p_{\text {nocaopy }}} / G_{p p_{\text {canopy }}}\right)$. Figure 7 shows the side-view schematic of canopy placed over microphones in a streamwise array with leading edge velocity profile varying for a range of maximum boundary layer edge velocities of $6.3-16.8 \mathrm{~m} / \mathrm{s}$. The uncertainty associated with the measured pressure spectral density was $2.2 \mathrm{~dB}$ at a jet exit velocity of $20 \mathrm{~m} / \mathrm{a}$ accounting for $0.5 \mathrm{~dB}$, due to placement of the microphone, 1 $\mathrm{dB}(20 \mathrm{~m} / \mathrm{s})$ to $0.3 \mathrm{~dB}(50 \mathrm{~m} / \mathrm{s})$, due to the flow conditions, $0.25 \mathrm{~dB}$ due to uncertainty of the measurement system and $0.5 \mathrm{~dB}$ due to calibration uncertainty. We observed a reduction in the uncertainty with increasing jet speed to an overall value of $0.3 \mathrm{~dB}$ at a jet exit velocity of $50 \mathrm{~m} / \mathrm{s}$.

All canopies given in Table 2 were tested for different heights, $h$ of $2 \mathrm{~mm}, 4 \mathrm{~mm}, 6 \mathrm{~mm}, 8 \mathrm{~mm}, 12 \mathrm{~mm}$ and $15 \mathrm{~mm}$ and jet velocity ranging from $20-50 \mathrm{~m} / \mathrm{s}$ in increments of $10 \mathrm{~m} / \mathrm{s}$ corresponding to measurements performed by Gonzalez et al 2019. The above tests correspond to arrangement of canopy rods such that they are parallel to the wall, therefore leading-edge angle is zero degrees. Data presented here correspond to streamwise microphone array shown in Figure 7. 


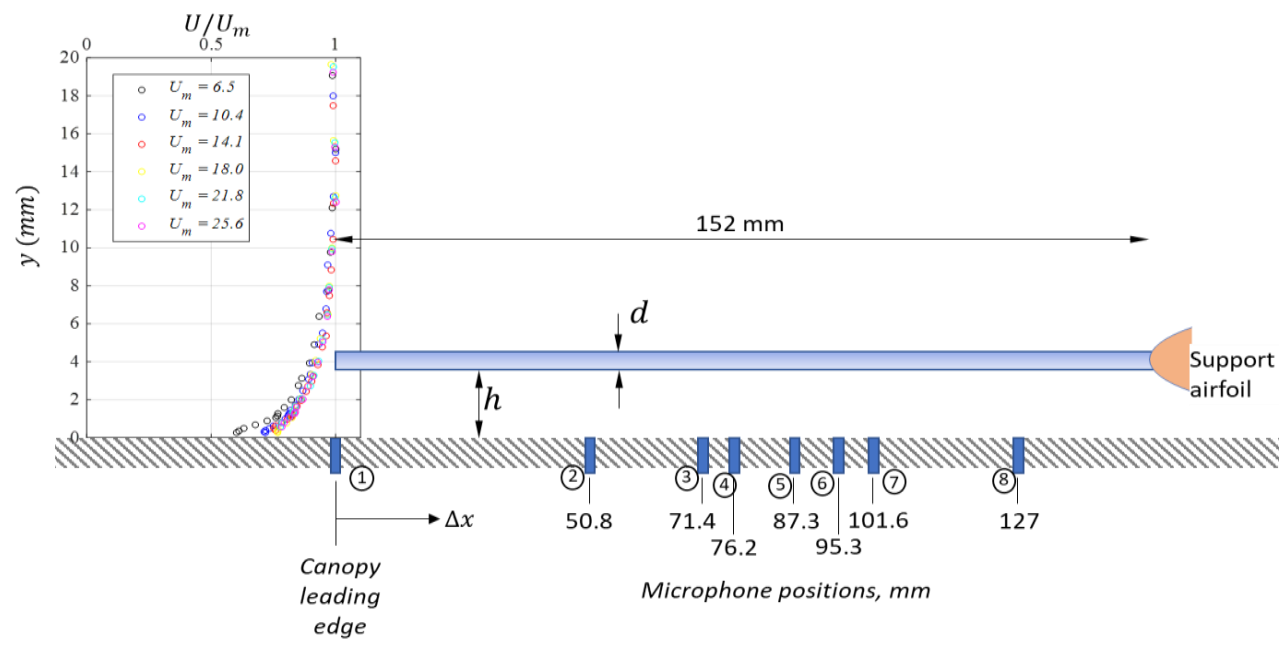

Figure 7: Parallel canopy arrangement and microphone positions for the horizontal canopy measurements. Mean velocity profiles show undisturbed flow at the canopy leading edge inferred from profiles measured at $x=1.13 \mathrm{~m}$ (Gonzalez et al (2019))

\section{Results and Discussion}

\section{A. Surface Pressure Spectra}

The results presented in the following sections include measurements shown in Gonzalez et al (2019) and new measurements conducted using canopies $\mathrm{D}, \mathrm{E}$ and $\mathrm{F}$ for wall jet flow velocity, $U_{j}$ ranging from $20-50 \mathrm{~m} / \mathrm{s}$. All canopies when placed over a smooth wall in a turbulent walljet boundary layer exhibit broadband attenuation in the unsteady surface pressure fluctuations. Figure 8 shows the surface pressure spectra and the attenuation spectra plotted as a function of frequency, $f(\mathrm{~Hz})$, for all canopies tested, A-F, at a height of $6 \mathrm{~mm}$ and normalized streamwise distance, $\Delta x / h$ of 17 for $U_{j}$ of $30 \mathrm{~m} / \mathrm{s}$ and $50 \mathrm{~m} / \mathrm{s}$. For all these canopies, at lower frequencies, $f$ of $100-600 \mathrm{~Hz}$, there is an increase in attenuation with frequency, reduction in attenuation in the mid-frequencies, $f$ of $600-2 \mathrm{kHz}$ followed by an increase in attenuation at the higher frequencies, $f>2 \mathrm{kHz}$. The intensity of attenuation is observed to vary significantly with change in canopy diameter and the open-area ratio. There is a broadband effect of these parameters on the intensity of attenuation. At a given velocity, the low frequency peak attenuation is attained at nearly the same frequency for all the canopies, which is at $300 \mathrm{~Hz}$ and $600 \mathrm{~Hz}$ for $30 \mathrm{~m} / \mathrm{s}$ and $50 \mathrm{~m} / \mathrm{s}$ respectively. The spread of the attenuation spectra in the high frequency is larger than the spread at lower frequencies indicating there are two dominant ranges of attenuation, which as we will see in subsequent section scale differently. For the same open-area ratio, canopies $\mathrm{A}, \mathrm{B}, \mathrm{D}$ and $\mathrm{E}$, the attenuation intensity reduces with increase in diameter size and a corresponding increase in spacing for the same velocity and canopy height. For the same flow velocity, the attenuation curves do not shift along the frequency axis. With increase in open-area ratio, comparing canopies A, B, D, E $(s / d=3)$ with canopies $\mathrm{B}(s / d=4)$ and $\mathrm{F}(s / d=8)$, there is reduction in the attenuation intensity. An increase in the open-area ratio corresponds to decrease in the planform area thus reduced 'blocking' of vertical momentum transfer. In addition to the two frequency ranges we recognize a third range, also the mid-freqeuncy range, where the attenuation reduces before starting to rise again at higher frequencies. 

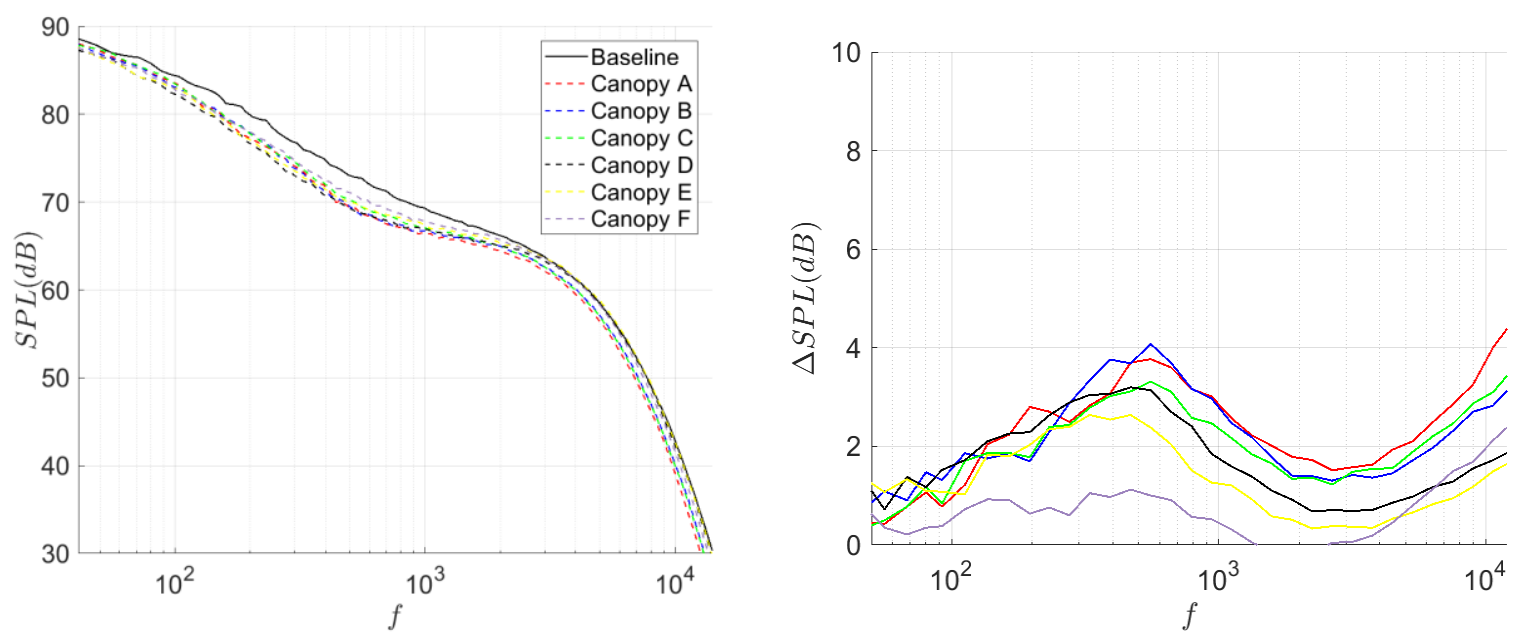

Figure 8: Surface pressure spectrum plotted as SPL $(\mathrm{dB})$ and the corresponding attenuation plotted as a function of the frequency for canopies A-F tested at height $6 \mathrm{~mm}$, streamwise distance, $\Delta x=101.6 \mathrm{~mm}$ and jet velocity of $50 \mathrm{~m} / \mathrm{s}$ respectively.

\section{B. Scaling Hypothesis}

For a canopy placed in a turbulent boundary layer, the pressure is expected to have a functional form:

$$
p^{\prime}=f\left(p_{n c}^{\prime}, U_{h}, U_{m}, \delta, v, s, d, h, \Delta x, \omega \ldots\right)
$$

Where, $U_{h}$ is the mean flow velocity at the canopy leading edge, measured at the height of the canopy and $U_{m}$, is the maximum mean flow velocity in the boundary layer measured at the canopy leading edge. $\delta$ is the walljet boundary layer thickness, $v$ is the kinematic viscosity, $s, d$ and $h$ are the canopy spacing, diameter and the height respectively. $\Delta x$ is the streamwise distance measured from the canopy leading edge and $\omega$ is the frequency scale associated with the flow. Based on these parameters, we can predict some meaningful non-dimensional parameters,

$$
\frac{p^{\prime}}{p_{n c}^{\prime}}=f\left(\frac{\Delta x}{h}, \frac{s}{d}, \frac{d}{h}, \frac{\omega v}{U^{2}}, \frac{\omega h}{U}, \frac{\delta}{h}\right)
$$

$\Delta x / h$ represents the streamwise distance normalized over the height and this is a crucial parameters governing the leading edge development of attenuation (Gonzalez 2019). $s / d$ represents the permeability of the canopy to vertical transfer of momentum, $d / h$ represents the blockage experienced by the flow and appears to govern the intensity of attenuation at all frequencies. $\omega v / U^{2}$ represents the dissipation like scale which we hypothesize to govern the highfrequency spectra. $\omega h / U$ is the Strouhal number based on the height of the canopy and $\delta / h$ is the ratio of boundary layer thickness and canopy height.

We hypothesize, consistent with prior studies where the velocity field has been examined, that the incoming flow is slowed down below the canopy due to friction by both the canopy and the wall surfaces, while the mean streamwise flow above the canopy remains largely unchanged. The slowing of the velocity beneath the canopy has two effects. First it results in lifting-up of the mean flow. The pressure fluctuations at the wall produced by turbulence structures carried with this mean flow will therefore be reduced. Second, the reduction in velocity under the canopy reduces near-wall mean velocity gradients and thus reduce the impact of the linear term in the pressure Poisson's equation. The following sections attempts to experimentally and theoretically analyze the flow-field and the important parameters controlling attenuation.

\section{Low-frequency attenuation}

At low frequencies, ranging from $f h / U_{h}$ of 0.01 to 0.2 , it was shown by Gonzalez et al (2019), that the attenuation scales with Strouhal number based on the canopy height and boundary layer velocity, given by $f h / U_{m}$. The scaling 
also worked well for velocity scales as $U_{h}$, flow velocity at canopy height measured at the streamwise location of canopy leading edge. Figure 9 shows the attenuation spectra plotted against low-frequency scaling of $f h / U_{h}$ for canopies A-F at jet speeds ranging $20-50 \mathrm{~m} / \mathrm{s}$ at a representative canopy height of $6 \mathrm{~mm}(\Delta x / h=17)$ and streamwise location of $\Delta x=101.6 \mathrm{~mm}$. The scaling appears to accurately align the frequency dependence of the attenuation, though it is clear that there is some variation in actual attenuation values at each frequency depending on canopy parameters. The peak attenuation for the canopies occurs near $f h / U_{h}$ of 0.2 for all flow speeds. (This is also consistent at different $\Delta x / h$ values tested.) However, we can observe a slight shift in the location of the frequency of the attenuation peak towards lower values with increase in canopy diameter. For the same open-area ratio, comparing canopies A, B, D and E, the attenuation reduces with increasing canopy rod diameter. For the same rod diameters (canopies $\mathrm{A}, \mathrm{C}$ and $\mathrm{F}$ ), we observe a reduction in the attenuation with increasing open-area ratio of $0.7 \mathrm{~dB}$ and $2.5 \mathrm{~dB}$ at $f h / U_{h}=0.2$ as the open area ratio is increased from 0.66(canopy), to 0.75 (canopy C) to 0.88 (canopy F). Therefore, we observe that both the open-area $\operatorname{ratio}(s / d)$ and $d / h($ or $s / h)$ appear to be controlling attenuation for the same $\Delta x / h$ value.

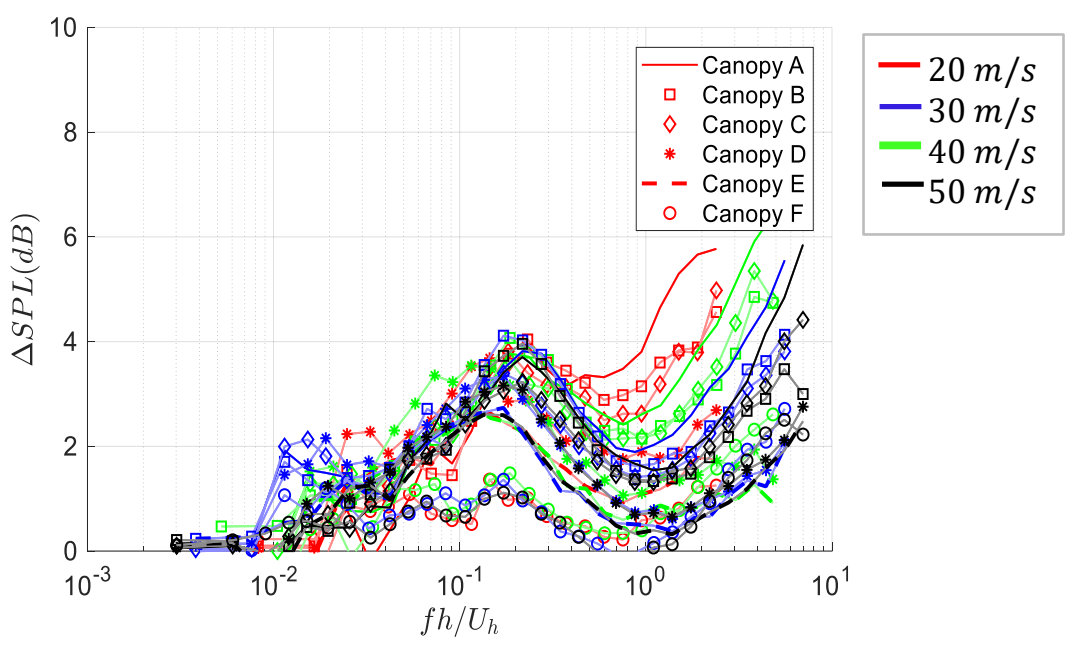

Figure 9: Surface pressure attenuation plotted as a function of the low-frequency scaling $\left(f h / U_{h}\right)$ for canopies A-F tested at jet velocities $20-50 \mathrm{~m} / \mathrm{s}$. The canopies have a height of $6 \mathrm{~mm}$ and the data is measured at a streamwise distance of $\Delta \mathrm{x} / \mathrm{h}=17$

Figure 10 shows the attenuation spectra plotted against low-frequency scaling of $f h / U_{h}$ for canopies A-F at jet speeds ranging $20-50 \mathrm{~m} / \mathrm{s}$ at heights $8 \mathrm{~mm}(\Delta x / h=12.7)$ and $12 \mathrm{~mm}(\Delta x / h=8.5)$ and streamwise location of $\Delta x=$ $101.6 \mathrm{~mm}$. With increase in height, and reduction in $\Delta x / h$, we observe there is a broadband reduction in the attenuation magnitude for all canopies tested. However, the low frequency scaling appears to consistently align the low-frequency variations (though not their levels) for $f h / U_{h}$ values ranging 0.02 to 0.2 . For the same $d / h$ values e.g. canopy $\mathrm{A}(d=1 \mathrm{~mm})$ at height $6 \mathrm{~mm}$ in Figure 9 and canopy $\mathrm{D}(d=2 \mathrm{~mm})$ at height $12 \mathrm{~mm}$ in Figure $10 \mathrm{~b}$, with $d / h$ value of 0.13 , the attenuation is significantly different. Therefore, for the same open-area ratio, variation in $\Delta x / h$ seems to be a dominant factor in controlling attenuation.

The variations of the low-frequency peak attenuation with $\Delta x / h$ for canopies A-F at heights of 4 to $15 \mathrm{~mm}$ are plotted in Figure 11 shown below. Initially, we observe a roughly linear increase in peak attenuation magnitude with $\Delta x / h$ which is independent of canopy height. Beyond $\frac{\Delta x}{h} \approx 15$ to 20 , the attenuation for canopies A, B and C appears to saturate and does not further increase with increase in $\Delta x / h$. This is clearly visible for canopies A-C where data is available at higher values of $\Delta x / h$. The canopies A and B which have the same open-area ratio, show slope of nearly 0.25 in the developing region. Canopy D shows a slightly lower slopes possibly suggesting that the development of attenuation for the same-open area ratio is slower with increasing canopy diameter. Additionally, the peak attenuation reduces with increase in canopy diameter for the same open-area ratio and same $\Delta x / h$ value. Looking at different open-area ratios, canopies $\mathrm{C}$ and $\mathrm{F}$ show a significant reduction in the rate of increase of peak attenuation with $\Delta x / h$. 
Canopy F, with the highest open area ratio (0.88) shows significantly lower attenuation for all $\Delta x / h$ values. The peak attenuation lies between the two frequency ranges, the lower and mid-frequency regions, therefore there would perhaps be a combination of two mechanisms, controlling the attenuation values.

Based on our hypothesis, the flow below the canopy is slowed due to interaction with the canopy structure and the wall. Considering a control volume as shown in Figure 12 with velocity components $U$, in the x-direction and $\mathrm{V}$, in the y-direction and noted with a subscript denoting the control volume face. $U_{1}$ is the flow entering the control volume through face $1, U_{2}$ and $V_{2}$ are the $x$ and $y$ velocity components respectively on face 2 and $U_{3}$ is the flow velocity leaving the control volume through face $3 . U_{L}$ is the flow below the canopy leaving control volume at face 3.

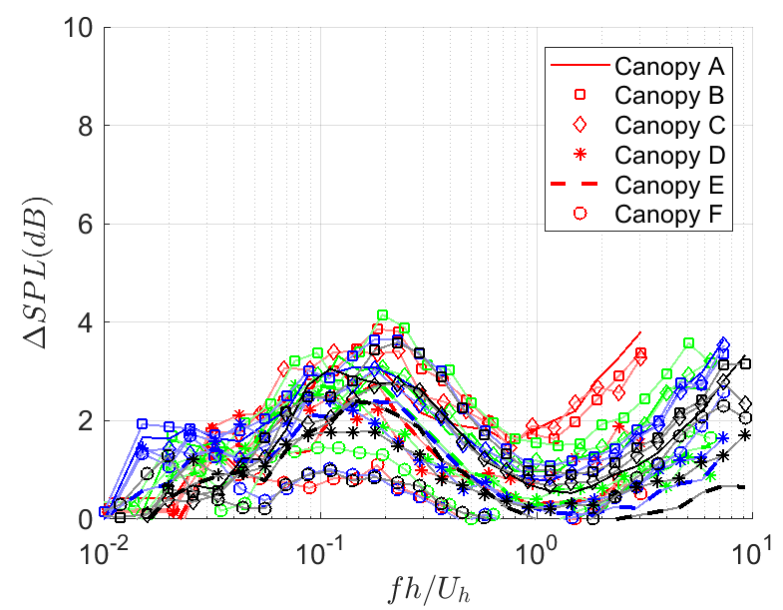

a)

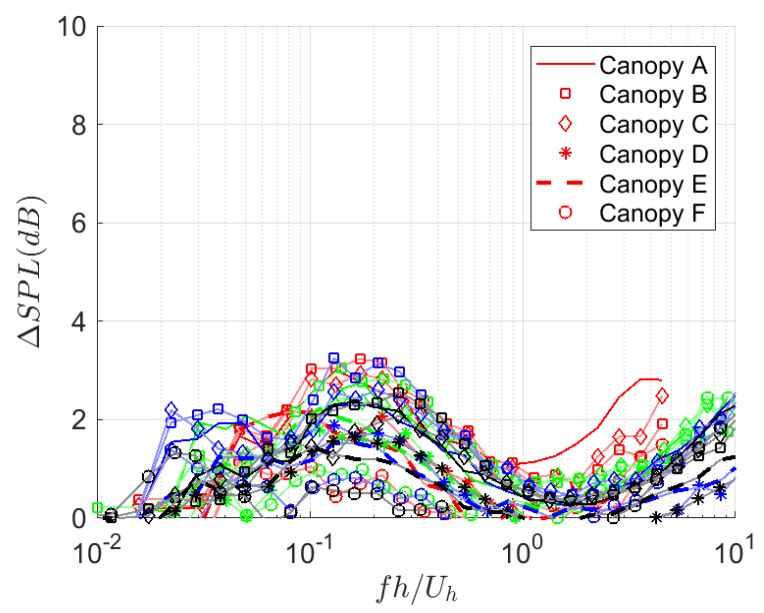

b)

Figure 10: Surface pressure attenuation plotted as a function of the low-frequency scaling $\left(f h / U_{h}\right)$ for canopies A-F tested at jet velocities $20-50 \mathrm{~m} / \mathrm{s}$. The canopies have heights of a) $8 \mathrm{~mm}$ and b) $12 \mathrm{~mm}$, and the data is measured at a streamwise distance of $\Delta \mathrm{x} / \mathrm{h}=17$

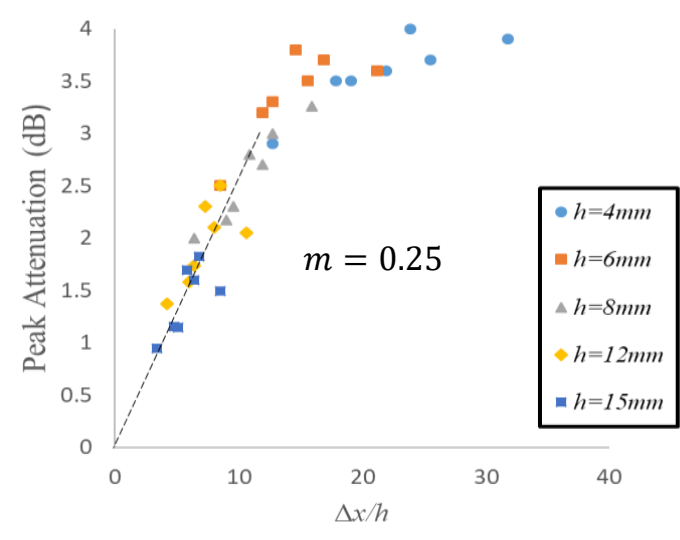

a) Canopy A $(d=1 \mathrm{~mm}, \mathrm{~s}=$

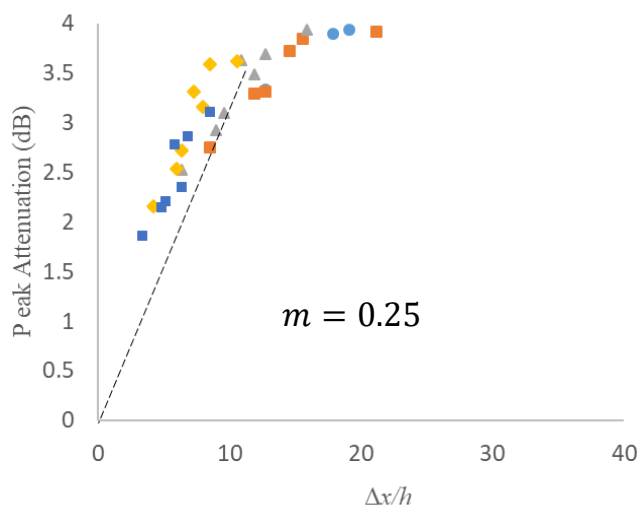

b) Canopy B $(d=1.56 \mathrm{~mm}, \mathrm{~s}=3.64 \mathrm{~mm})$ 

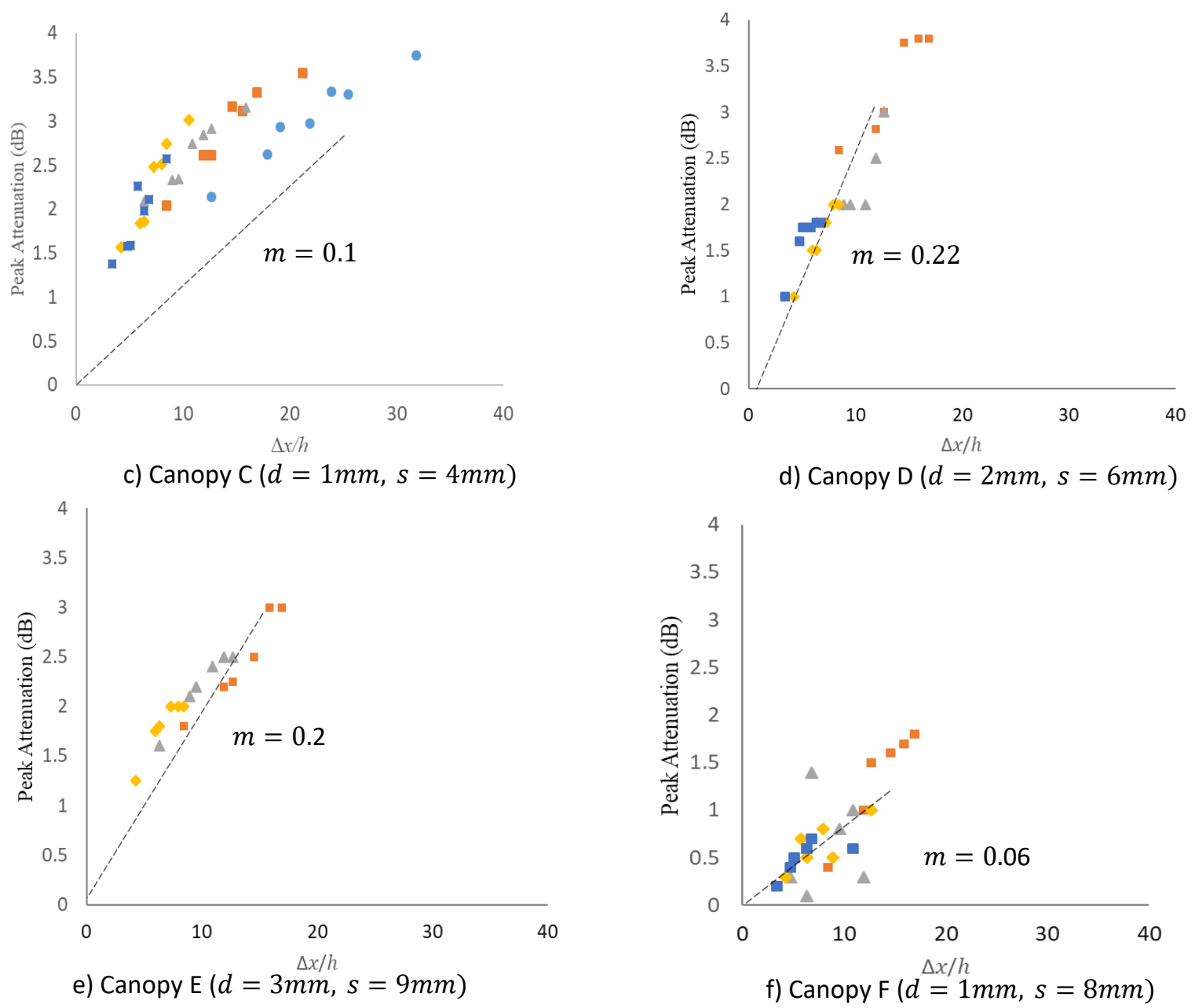

Figure 11: Low frequency attenuation peak plotted as a function of $\Delta x / h$ for canopies $\mathrm{A}, \mathrm{B}, \mathrm{C}, \mathrm{D}, \mathrm{E}$ and $\mathrm{F}$

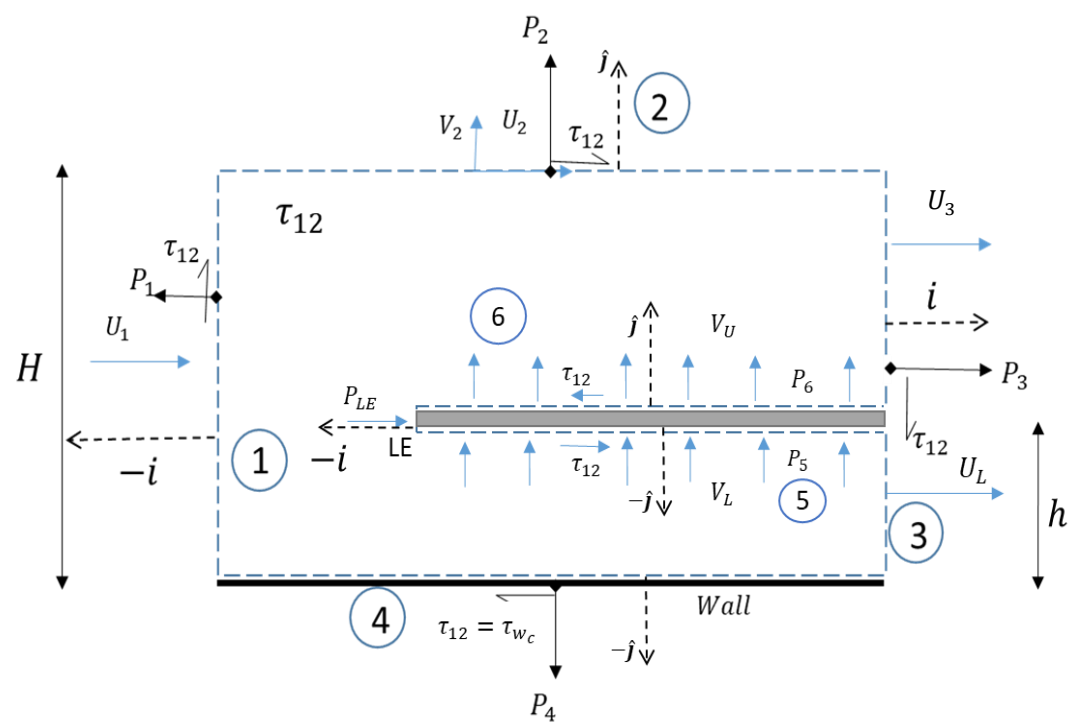

Figure 12: Control volume enclosing the canopy placed over a flat surface characterized by incoming flow through face 1, outgoing flow through surface 3 and surface wall along the wall. The canopy surfaces are marked as 4 and 5 
Assuming uniform velocities and the velocities and pressures above the canopy to be largely unchanged, we obtain the lift-up distance, $\Delta$, of the mean flow as,

$$
\Delta=h\left(1-\frac{U_{L}}{U_{1}}\right)
$$

Using a momentum balance on this control volume the flow velocity below the canopy $U_{L}$ can be estimated by assuming a skin friction coefficient on the canopy rods and wall.

The change in the velocity gradient assuming uniform flow, $U_{L}$ at the wall will be proportional to the ratio of change in velocity at the wall by the vertical lift-up distance of the flow given by, $U_{L} / \Delta$. If we scale the frequency as $f \Delta / U_{L}$ instead of $f h / U_{h}$, we obtain Figure 13, which shows the attenuation spectra plotted against low-frequency scaling of $f \Delta / U_{L}$ for canopies A-F at jet speeds ranging $20-50 \mathrm{~m} / \mathrm{s}$ at heights $6 \mathrm{~mm}$ and streamwise location of $\Delta x=101.6 \mathrm{~mm}$. $U_{1}$ used here corresponds to the unchanged $U_{m}$ value measured at the canopy height. The coefficients of friction for the canopy rods and the wall have been assumed to be a constant with a value of 0.003 . Figure 13 shows a collapse of the low-frequency attenuation $f \Delta / U_{L}$ of 0.02-0.1 at least compared to that achieved with the canopy-height scaling in Figure 9. However, we observe that the peak attenuation does not occur at the same $f \Delta / U_{L}$ value. Therefore, we observe in terms of the peak attenuation, $f h / U_{h}$ seems to be more appropriate.

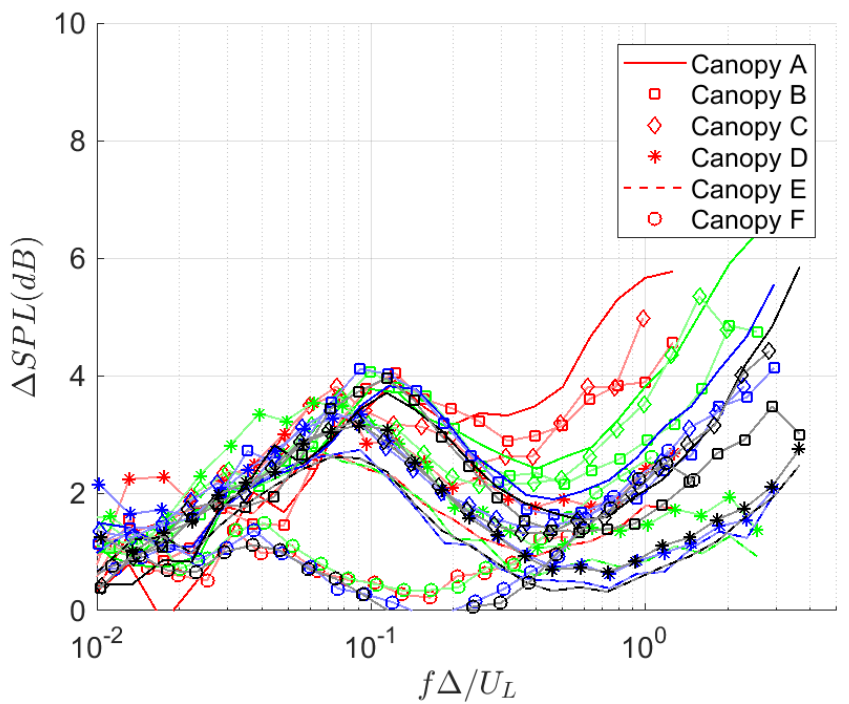

Figure 13: Surface pressure attenuation plotted as a function of the low-frequency scaling $\left(f \Delta / U_{L}\right)$ for canopies A-F tested at jet velocities $20-50 \mathrm{~m} / \mathrm{s}$. The canopies have a height of $6 \mathrm{~mm}$, and the data is measured at a streamwise distance of $\Delta \mathrm{x} / \mathrm{h}=17$

Figure 14 which shows the attenuation spectra plotted against low-frequency scaling of $f \Delta / U_{L}$ for canopies A-F at jet speeds ranging $20-50 \mathrm{~m} / \mathrm{s}$ at heights $8 \mathrm{~mm}$ and $12 \mathrm{~mm}$ and streamwise location of $\Delta x=101.6 \mathrm{~mm}$. The scaling appears to work somewhat better than the canopy height scaling in Figure 10. 

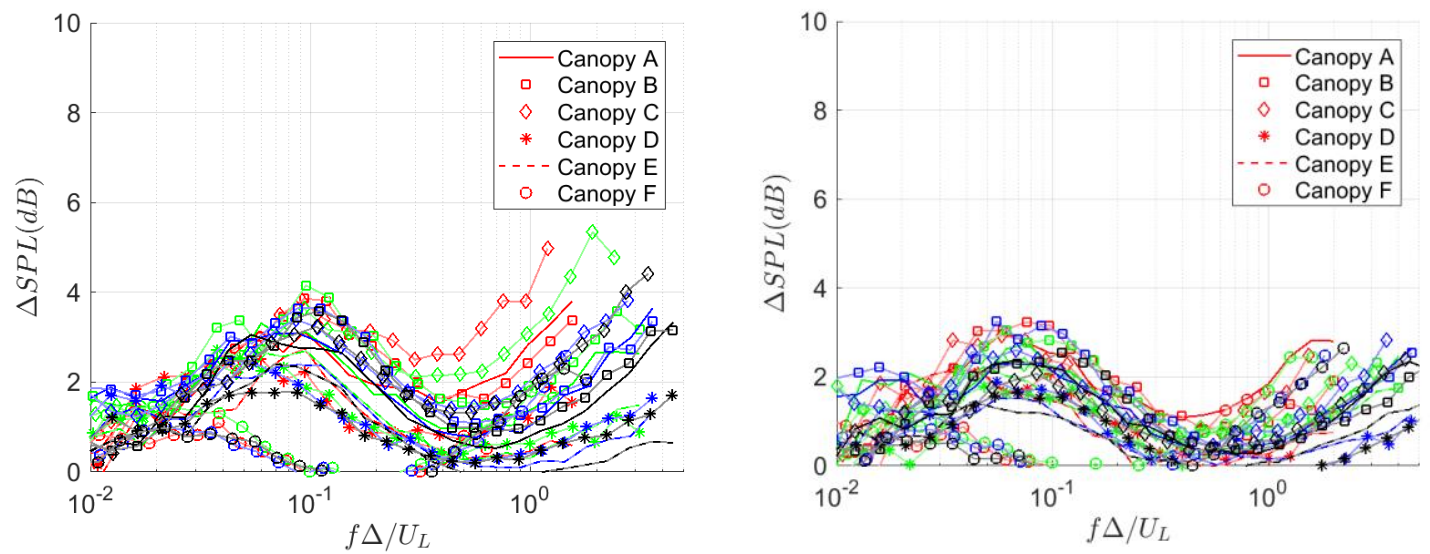

Figure 14: Surface pressure attenuation plotted as a function of the low-frequency scaling $\left(f \Delta / U_{L}\right)$ for canopies A-F tested at jet velocities $20-50 \mathrm{~m} / \mathrm{s}$. The canopies have a height of $8 \mathrm{~mm}$ and $12 \mathrm{~mm}$, and the data is measured at a streamwise distance of $\Delta \mathrm{x} / \mathrm{h}=17$

\section{Mid-frequency attenuation}

The mid-frequency region which is characterized by reduction in attenuation, observed for all canopies tested for frequencies ranging between $600-2 \mathrm{kHz}$. We hypothesize the dip in attenuation is caused due to production of turbulence by the canopy. Therefore, we can attempt to scale this region by the Strouhal number based on the length scale associated with the turbulence generated. The canopy possibly breaks down the larger turbulent structures to length scales associated with the rod diameter and spacing. Figure 15 shows mid-frequency attenuation plotted against Strouhal number based on the diameter and $U_{h}$ given by, $f d / U_{h}$, for all canopies tested at jet velocities $20-50 \mathrm{~m} / \mathrm{s}$, canopy height of $6 \mathrm{~mm}$ and normalized streamwise distance of $\Delta x / h=17$. We observe that there is a spread of attenuation of $2 \mathrm{~dB}$ in the mid-frequency region $\left(0.05<f d / U_{h}<0.2\right)$, for all cases except canopy $\mathrm{F}$, which does not scale at all. Plotting attenuation with Strouhal number scaling based on the canopy spacing instead, gives a better collapse of attenuation data in the mid-frequency region with lesser spread of $0.5 \mathrm{~dB}$ as shown in Figure 16, with the exception, again, of canopy $\mathrm{F}$.

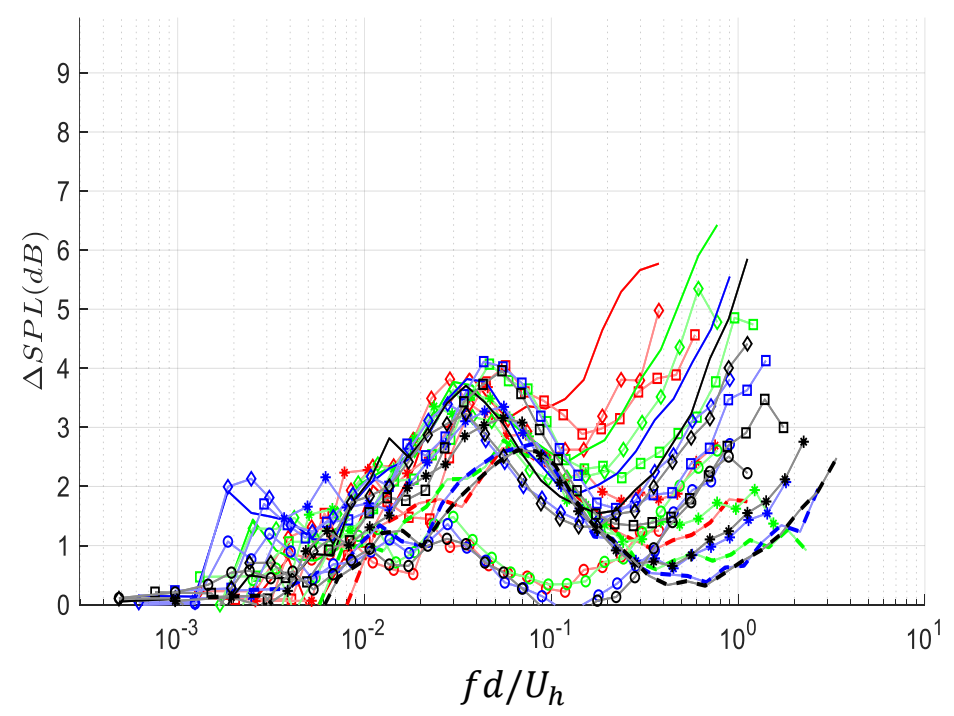

Figure 15: Surface pressure attenuation plotted as a function of normalized frequency $\left(f d / U_{h}\right)$ for canopies A-F tested at jet velocities of $20-50 \mathrm{~m} / \mathrm{s}$. The data is measured for canopy height $6 \mathrm{~mm}$ at a streamwise distance of $\Delta \mathrm{x} / \mathrm{h}=17$ 


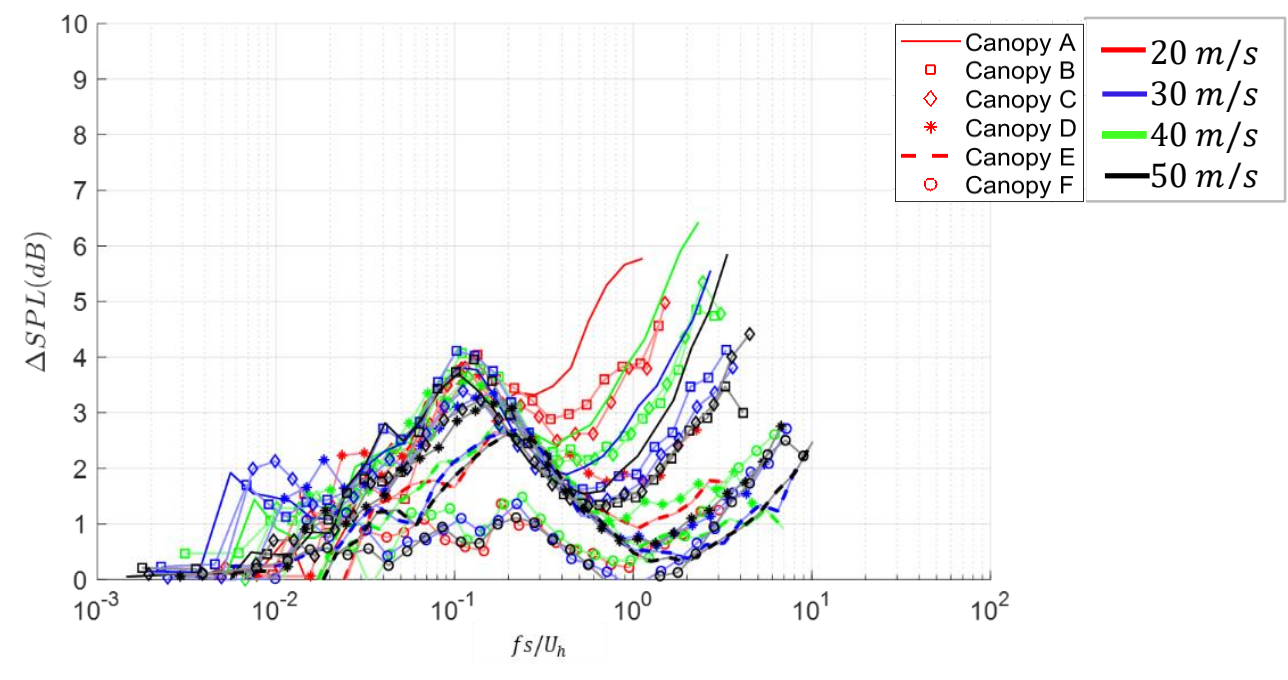

Figure 16: Surface pressure attenuation plotted as a function of normalized frequency $\left(f s / U_{h}\right)$ for canopies AF tested at jet velocities of $20-50 \mathrm{~m} / \mathrm{s}$. The data is measured for canopy height $6 \mathrm{~mm}$ at a streamwise distance of $\Delta \mathrm{x} / \mathrm{h}=17$

\section{High-frequency attenuation}

The high frequency region of the spectrum, $f>2 \mathrm{kHz}$ is thought to be associated with the viscous action in the flow. We first attempt to scale the attenuation as a function of $f v / U_{h}^{2}$, based on conventional dissipative scaling used for high frequency turbulent boundary layer surface pressure spectra, Figure 17. The normalization $f v / U_{h}^{2}$ approximately scales the frequency of the attenuation minimum near $f v / U_{h}^{2}$ of $2 \mathrm{e}-4$. However, the attenuation curves do not collapse on the same curve.

Searching through the list of flow parameters, the high frequency attenuation appears to scale best when plotted against $\left(f v / U_{h}^{2}\right)(\Delta x / s)$. This is derived from by multiplying $\left(f v / U_{h}^{2}\right)$ by non-dimensional parameters of open-area ratio $s / d$, streamwise distance $\Delta x / h$ normalized by the height and $d / h$, ratio of canopy diameter and the height. Figure 18 shows the attenuation plotted against $\left(f v / U_{h}^{2}\right)(\Delta x / s)$ for all canopies tested at jet velocities ranging $20-50 \mathrm{~m} / \mathrm{s}$, canopy height of $6 \mathrm{~mm}$ and measures at a streamwise location of $\Delta x / h=17$. This was observed to approximately scale the higher frequency attenuation for normalized frequencies greater than about 0.02 .

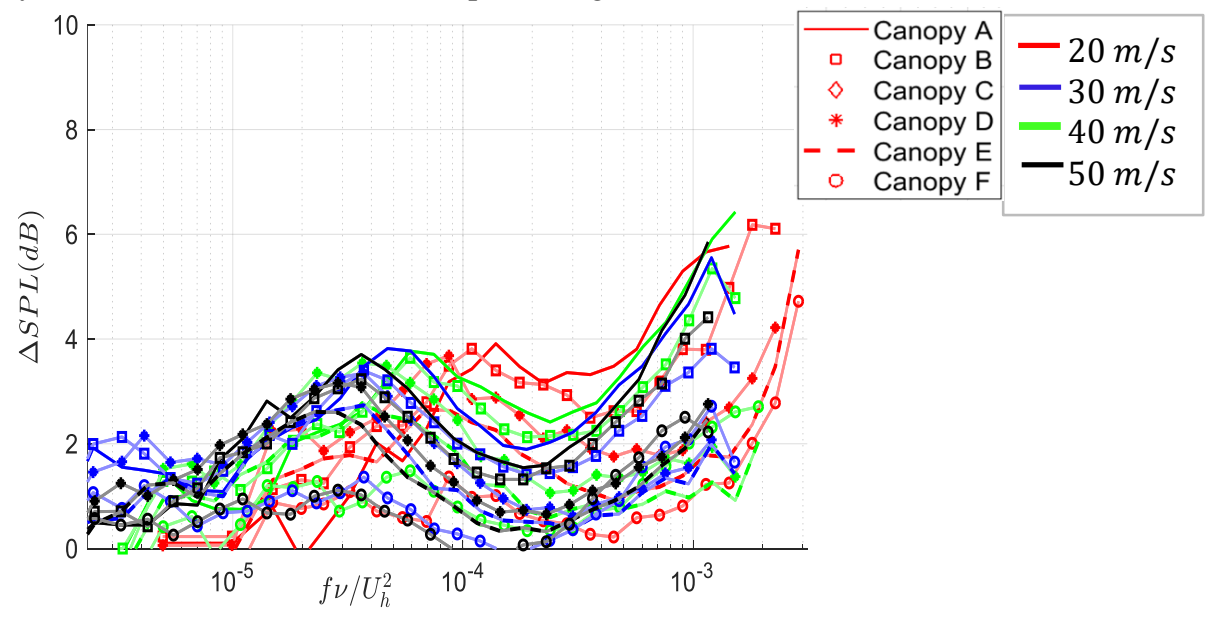

Figure 17: Surface pressure attenuation plotted as a function of normalized frequency $\left(f v / U_{h}^{2}\right)$ for canopies A-F tested at jet velocities $20-50 \mathrm{~m} / \mathrm{s}$. The data is measured for $h=6 \mathrm{~mm}$ at a streamwise distance of $\Delta \mathrm{x} / \mathrm{h}=17$ 


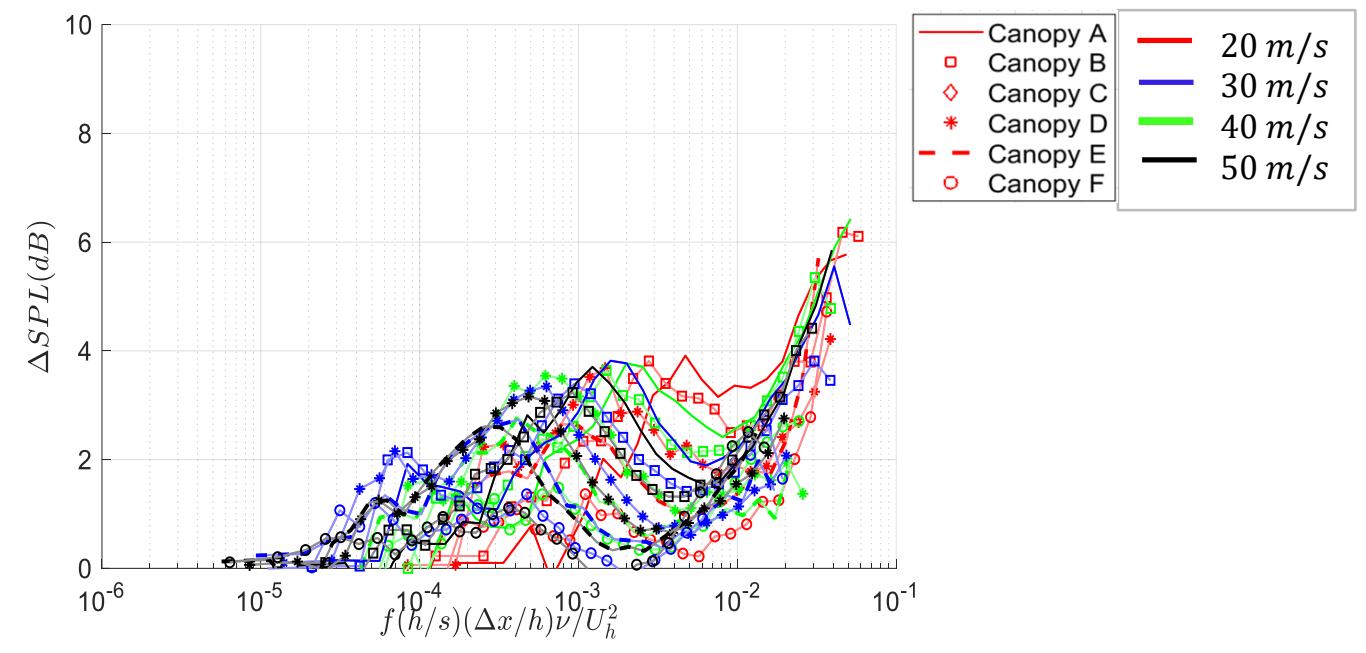

Figure 18: Surface pressure attenuation plotted as a function of normalized frequency $\left(f v\left(\frac{\Delta x}{s}\right) / U_{h}^{2}\right)$ for canopies A-F tested at jet velocities $20-50 \mathrm{~m} / \mathrm{s}$. The data is measured for $h=6 \mathrm{~mm}$ at a streamwise distance of $\Delta \mathrm{x} / \mathrm{h}=17$

\section{Conclusion}

Experimental studies on unidirectional, elemental canopy configurations, which are parallel arrays of streamwise rods show three regions of attenuation in the wall pressure frequency spectrum beneath the canopy. Dependence of attenuation on non-dimensional parameters open-area ratio, $s / d$, ratio of rod diameter and canopy height, $d / h$ and streamwise distance normalized by the canopy height, $\Delta x / h$ has been investigated. It is hypothesized that the canopy slows the flow beneath it. The difference in the streamwise velocity causes the flow to lift-up. The pressure fluctuations at the wall produced by turbulence structures carried with this mean flow will therefore be reduced. The reduction in velocity under the canopy also reduces near-wall mean velocity gradients and thus reduce the impact of the linear term in the pressure Poisson's equation. Attenuation is reduced at mid frequencies, possibly because of new turbulence generated by the canopy. The frequency dependence of the attenuation at low frequencies appears to scale when frequency is normalized on the canopy height and upstream flow velocity (as observed by Gonzalez et al. (2019)), but the correlation is slightly improved if the velocity below the canopy and the lift-up distance of the flow are used as the normalizing variables. The low-frequency attenuation increases with distance downstream from the canopy leading edge $\Delta x / h$ when other parameters are held fixed and reduces with increase in open area ratio, canopy rod diameter and spacing. The rate at which the attenuation increases with $\Delta x / h$ reduces with open area ratio. At mid frequencies, the reduction in attenuation attributed to new turbulence production is approximately scaled with frequency normalized using canopy rod spacing. In the high frequency region dissipation-type scaling is observed, but the exact dependence is still not understood. PIV measurements of the flow around and beneath these canopies are currently underway. It is hoped that observations about the flow and turbulence structure will at both detail and insight to the dependencies observed in the wall pressure fluctuations.

\section{Acknowledgements}

The authors would like to thank the National Science Foundation, in particular Dr. Ron Joslin, for their support of this research under grant CBET-1802915.

\section{Reference}

1. Clark, I. A., Daly, C. A., Devenport, W., Alexander, W. N., Peake, N., Jaworski, J. W., and Glegg, S. "Bioinspired canopies for the reduction of roughness noise," Journal of Sound and Vibration Vol. 385, 2016, pp. 33-54.

2. Clark, I. A., Alexander, W. N., Devenport, W., Glegg, S., Jaworski, J. W., Daly, C., and Peake, N. "Bioinspired Trailing-Edge Noise Control," AIAA Journal Vol. 55, No. 3, 2017, pp. 740-754. 
3. Millican, A. J., Clark, I., Devenport, W. J., and Alexander, W. N. "Owl-Inspired Trailing Edge Noise Treatments: Acoustic and Flow Measurements," 55th AIAA Aerospace Sciences Meeting. Grapevine TX, 2017.

4. Afshari, A., Azarpeyvand, M., Dehghan, A. A., and Szoke, M. "Trailing Edge Noise Reduction Using Novel Surface Treatments," 22nd AIAA/CEAS Aeroacoustics Conference. Lyon, France, 2016.

5. Afshari, A., Azarpeyvand, M., Dehghan, A. A., and Szoke, M. "Effects of Streamwise Surface Treatments on Trailing Edge Noise Reduction," AIAA Aviation 17. Denver, CO, 2017.

6. Bodling, A., Agrawal, B. R., Sharma, A., Clark, I., Alexander, W. N., and Devenport, W. J. "Numerical Investigations of Bio-Inspired Blade Designs to Reduce Broadband Noise in Aircraft Engines and Wind Turbines," 55th AIAA Aerospace Sciences Meeting. Grapevine, TX, 2017.

7. Bodling, A., Agrawal, B. R., Sharma, A., Clark, I., Alexander, W. N., and Devenport, W. J. "Numerical Investigation of Bio-Inspired Blade Designs at High Reynolds Numbers for Ultra-Quiet Aircraft and Wind Turbines," AIAA Aviation 17. Denver, CO, 2017.

8. Gonzalez, A., Glegg, S. A., Hari, N., \& Devenport, W. J. (2019). Fundamental Studies of the Mechanisms of Pressure Shielding. In 25th AIAA/CEAS Aeroacoustics Conference (p. 2403).

9. Jacobs, R. G., and Durbin, P. A. "Shear sheltering and the continuous spectrum of the Orr-Sommerfeld equation," Physics of Fluids Vol. 10, No. 8, 1998, pp. 2006-2011.

10. Hunt, J. C. R., and Durbin, P. A. "Perturbed vortical layers and shear sheltering," Fluid Dynamics Research Vol. 24, 1999, pp. 375-404.

11. Raupach, M. R., Finnigan, J. J., and Brunet, Y. "Coherent eddies and turbulence in vegetation canopies: the mixing-layer analogy," Bound. Layer Meterol. Vol. 78, No. 3-4, 1996, pp. 351-382.

12. Lumley, J. L. (1969). Drag reduction by additives. Annual review of fluid mechanics, 1(1), 367-384.

13. Ptasinski, P. K., Boersma, B. J., Nieuwstadt, F. T. M., Hulsen, M. A., Van den Brule, B. H. A. A., \& Hunt, J. C. R. (2003). Turbulent channel flow near maximum drag reduction: simulations, experiments and mechanisms. Journal of Fluid Mechanics, 490, 251-291.

14. Finnigan, J. "Turbulence in Plant Canopies," Annu. Rev. Fluid Mech. Vol. 32, 2000, pp. 519-571.

15. Belcher, S. E., Harman, I. N., and Finnigan, J. J. "The Wind in the Willows: Flows in Forest Canopies in Complex Terrain," Annual Review of Fluid Mechanics Vol. 44, No. 1, 2012, pp. 479-504.

16. Belcher, S. E., Jerram, N., and Hunt, J. C. R. "Adjustment of a turbulent boundary layer to a canopy of roughness elements," Journal of Fluid Mechanics Vol. 488, 2003, pp. 369-398.

17. Lilley, G. "A study of the silent flight of the owl," 1998.

18. Kaimal, J. C., \& Finnigan, J. J. (1994). Atmospheric boundary layer flows: their structure and measurement. Oxford university press

19. Poggi, D., \& Katul, G. G. (2006). Two-dimensional scalar spectra in the deeper layers of a dense and uniform model canopy. Boundary-layer meteorology, 121(2), 267-281.

20 Wygnanski, I., Katz, Y., \& Horev, E. (1992). On the applicability of various scaling laws to the turbulent wall jet. Journal of Fluid Mechanics, 234, 669-690.

21. Kleinfelter, A. W., Repasky, R., Hari, N., Letica, S., Vishwanathan, V., Organski, L., \& Devenport, W. J. (2019). Development and Calibration of a new Anechoic Wall Jet Wind Tunnel. In AIAA Scitech 2019 Forum (p. 1936).

22. Gonzalez, A. " A Computational Analysis of Bio-Inspired Modified Boundary Layers for Acoustic Pressure Shielding in A Turbulent Wall Jet", Ocean and Mechanical Engineering. MS, Florida Atlantic University, 2019. 